\title{
PLANTAS MEDICINAIS: A NECESSIDADE DE ESTUDOS MULTIDISCIPLINARES
}

\author{
Maria Aparecida M. Maciel*, Angelo C. Pinto e Valdir F. Veiga Jr.
}

Instituto de Química, Universidade Federal do Rio de Janeiro, CT, Cidade Universitária, 21945- 970 Rio de Janeiro - RJ

Noema F. Grynberg e Aurea Echevarria

Departamento de Química, Instituto de Ciências Exatas, Universidade Federal Rural do Rio de Janeiro, 23851-970 Seropédica - RJ

Recebido em 6/11/00; aceito em 25/7/01

\begin{abstract}
MEDICINAL PLANTS: THE NEED FOR MULTIDISCIPLINARY SCIENTIFIC STUDIES. This paper presents a program emphasizing ethnopharmacological approaches that could allow great success in the study of medicinal plants. The minimum ethnopharmacological research team should consist of a botanist, a chemist and a pharmacologist with each carrying the responsibility for answering in sequential fashion critical questions. The chemical composition and pharmacological properties of the very efficient medicinal plant Croton cajucara were investigated according to ethnopharmacological approaches. The study with this Croton proved to be both efficient and successful. This happy situation was only possible because a multidisciplinary team was involved getting the research done correctly. The ethnopharmacological study involving one other especies Copaifera will be cited.
\end{abstract}

Keywords: ethnopharmacology; phytochemistry; Croton cajucara; Copaifera.

\section{INTRODUÇÃO}

O conhecimento sobre plantas medicinais simboliza muitas vezes o único recurso terapêutico de muitas comunidades e grupos étnicos. $\mathrm{O}$ uso de plantas no tratamento e na cura de enfermidades é tão antigo quanto a espécie humana. Ainda hoje nas regiões mais pobres do país e até mesmo nas grandes cidades brasileiras, plantas medicinais são comercializadas em feiras livres, mercados populares e encontradas em quintais residenciais. Na região Amazônica foram catalogadas em duas comunidades que vivem nas margens da Baía de Marajó-PA, 260 plantas entre nativas e cultivadas; 1200 são comercializadas no mercado Ver-o-peso, em Belém-PA; outras 242 espécies são cultivadas em quintais residenciais, em Belém ${ }^{1,2}$. As observações populares sobre o uso e a eficácia de plantas medicinais contribuem de forma relevante para a divulgação das virtudes terapêuticas dos vegetais, prescritos com frequência, pelos efeitos medicinais que produzem, apesar de não terem seus constituintes químicos conhecidos. Dessa forma, usuários de plantas medicinais de todo o mundo, mantém em voga a prática do consumo de fitoterápicos, tornando válidas informações terapêuticas que foram sendo acumuladas durante séculos. De maneira indireta, este tipo de cultura medicinal desperta o interesse de pesquisadores em estudos envolvendo áreas multidiciplinares, como por exemplo botânica, farmacologia e fitoquímica, que juntas enriquecem os conhecimentos sobre a inesgotável fonte medicinal natural: a flora mundial.

Este artigo focaliza duas das mais importantes plantas medicinais brasileiras da atualidade: Croton cajucara Benth, uma euforbiácea, muito utilizada na medicina popular da região Amazônica, cujo uso vem sendo difundido por todo o país. Esta planta é encontrada em diferentes formulações nas farmácias de produtos naturais do Sudeste; e Copaifera L. (Leguminosae-Caesalpinoideae) cujo óleo, conhecido popularmente como óleo de copaíba, pode ser encontrado à venda em quase todas as feiras livres, mercados populares, ervanários e farmácias de produtos naturais de todo o país.

$\mathrm{O}$ artigo exemplifica a importância de estudos multidisciplinares com plantas medicinais, envolvendo a etnobotânica, a química e a farmacologia.

\footnotetext{
* e.mail: mammaciel@hotmail.com
}

\section{Abordagem etnobotânica}

O termo etnobotânica foi empregado pela primeira vez em 1895 por Harshberger, que embora não o tenha definido, apontou maneiras pelas quais poderia ser útil à investigação científica ${ }^{3}$. Desde então, várias definições podem ser encontradas para etnobotânica. Dentre as mais recentes destacam-se: a) "disciplina que se ocupa do estudo e conceituações desenvolvidas por qualquer sociedade a respeito do mundo vegetal" - engloba a maneira como um grupo social classifica as plantas e a utilidade que dá a elas"; b) "verdadeira botânica científica voltada para o hábitat e uso de uma etnia específica"sendo realizada por alguém treinado em botânica científica, que efetuaria correspondências entre a classificação científica ocidental e local'; c) "ciência botânica que possui uma etnia específica"- vê a cultura de uma sociedade como tudo aquilo que alguém tem que saber ou crer, a fim de operar de forma aceitável para seus mem$\operatorname{bros}^{5}$. A etnobotânica aplicada ao estudo de plantas medicinais trabalha em estreita cumplicidade com a etnofarmacologia, que consiste na exploração científica interdisciplinar de agentes biologicamente ativos, tradicionalmente empregados ou observados por determinado agrupamento humano ${ }^{6,7}$. Um dos pioneiros em estudos etnobotânicos, Richard Evans Schultes, dedicado à pesquisa da flora da América tropical, relata inúmeras espécies vegetais brasileiras usadas por caboclos e indígenas da Amazônia ${ }^{8-11}$.

A etnobotânica é citada na literatura como sendo um dos caminhos alternativos que mais evoluiu nos últimos anos para a descoberta de produtos naturais bioativos ${ }^{6,7,12-18}$. Esta área de pesquisa enfoca dois fatores fundamentais: coleta e utilização medicinal da planta. $\mathrm{O}$ primeiro fator implica na região, época e estágio de desenvolvimento preferidos para coleta, envolve também, procedimentos especiais como preparação de exsicatas. O depósito de exsicata em herbário credenciado é muito útil para evitar enganos com a espécie que está sendo estudada.

\section{Seleção de espécies vegetais}

Várias abordagens para a seleção de espécies vegetais têm sido apresentadas na literatura ${ }^{19-26}$, dentre elas, três tipos são alvo de maiores investigações: a) abordagem randômica - escolha da planta sem qualquer critério, tendo como fator determinante a disponibilidade 
da planta; b) abordagem quimiotaxonômica ou filogenética - seleção da espécie correlacionada com a ocorrência de uma dada classe química de substâncias em um gênero ou família; c) abordagem etnofarmacológica - seleção da espécie de acordo com o uso terapêutico evidenciado por um determinado grupo étnico. De acordo com a abordagem randômica 10000 diferentes tipos de plantas simbolizam 50000 - 100000 possibilidades estruturais de produtos naturais ${ }^{27,28}$. As probabilidades de novas descobertas de substâncias inéditas, bioativas ou não, é, sem dúvida, maior na seleção randômica. A seleção etnofarmacológica, no entanto, favorece com maior probabilidade a descoberta de novas substâncias bioativas. Nesta abordagem as plantas medicinais são consideradas não apenas como simples matéria prima. A descrição do histórico da planta como um recurso terapêutico eficaz para o tratamento e cura de doenças de determinado grupo étnico, se traduz na economia de tempo e dinheiro, dois dos fatores mais perseguidos pelas economias ocidentais.

\section{Conceitos básicos na pesquisa de plantas medicinais}

Em geral a escolha de uma determinada planta medicinal é feita através da abordagem etnofarmacológica. Uma vez definida a espécie vegetal a ser estudada, define-se também o local da coleta (origem da espécie vegetal escolhida: floresta amazônica; cerrado; mata atlântica; pantanal; caatinga; manguezal; etc.). Nesta fase inicial do trabalho científico, o pesquisador deve estar completamente inteirado da literatura sobre a planta escolhida, porque muitas vezes, plantas medicinais são investigadas parcialmente, validando, portanto, o interesse em novas investigações científicas. Por exemplo: a) se a espécie escolhida é encontrada em regiões diferentes no país, tornase importante avaliar as modificações químicas que possam ocorrer em decorrência de fatores ambientais variáveis, tais como: fertilidade do solo, umidade, radiação solar, vento, temperatura, herbivoria, poluição atmosférica e poluição do solo. Outros fatores como idade da planta e época de coleta, também poderão causar modificações nos teores dos constituintes químicos de espécies vegetais; b) se a espécie vegetal medicinal estudada sofreu apenas investigação fitoquímica, deixando de lado a abordagem farmacológica, são válidos estudos que interliguem áreas multidiciplinares como etnobotânica, química e farmacologia, buscando resultados que possam validar ou não o uso da planta como medicinal. Em quaisquer circunstâncias, a pesquisa bibliográfica da planta alvo deve ser realizada obedecendo-se os seguintes fatores: gênero, família e classes de substâncias predominantes.

Com a escolha da planta definida e o local de coleta estabelecido, o levantamento bibliográfico efetuado e o projeto de pesquisa elaborado, parte-se então, para a coleta da planta. A planta escolhida deve ser seguramente identificada. Para atender esta exigência, depende-se de outro especialista: um botânico ou um técnico especializado. A falta de identificação científica (ou uma identificação errônea) anulará todo o trabalho do químico, tornando-o impublicável e praticamente inútil. A coleta, portanto, deve constar de duas etapas: coleta prévia para a identificação botânica da espécie e a coleta definitiva quando se tratar de grandes quantidades de material, destinada para estudos fitoquímicos e/ou farmacológicos. Na etapa prévia, coleta-se pequenos ramos com folhas, flores e frutos em vários estágios de desenvolvimento. As amostras devem ser representativas do aspecto geral da planta, de modo que ramos com danos causados por insetos, fungos ou injúria mecânica, devem ser evitados, porém, se as amostras representativas estiverem com estes danos, devem ser coletadas assim mesmo, pois a representatividade é fator prioritário. As amostras coletadas são encaminhadas para um herbário, onde são prensadas e secas (no caso de não terem recebido este tratamento no local da coleta). Após identificação científica, a planta é cataloga- da contendo os seguintes itens: número de registro da exsicata; timbre da instituição; rótulo com etiqueta; amostra vegetal; envelope para flores e/ou frutos e capa de proteção. Concluída esta etapa inicial do trabalho, deve-se providenciar o seguinte registro de informações: 1) nome científico e família botânica; 2) nome de quem identificou a espécie; 3) número de registro da exsicata; 4) local do herbário; 5) local e data da coleta; 6) nome popular da planta; 7) anotar a parte da planta utilizada na medicina popular e suas indicações terapêuticas; 8) anotar o tipo de solo onde a planta foi coletada, tipo de vegetação local, tipo da planta (arbusto ou árvore), horário de abertura floral (no caso de conter flores), época de frutificação (no caso de conter frutos), cor e cheiro de várias partes da planta. Quando possível, deve ser tirada uma ou mais fotos da planta inteira no seu hábitat natural.

A segunda etapa de coleta, destinada ao estudo fitoquímico e/ou farmacológico, consta de uma única coleta ou várias coletas. Neste último caso, as coletas poderão ser realizadas em épocas diferentes do ano e/ou locais diferentes. Caso haja coleta em regiões diferentes, inicia-se novamente todo o processo de identificação botânica, porque muitas vezes plantas diferentes são conhecidas popularmente pelo mesmo nome.

$\mathrm{Na}$ etapa que determina o estudo fitoquímico, escolhe-se a parte da planta que será investigada (raiz, cascas do caule, caule, galhos, folhas, flores, frutos) e a quantidade de material que será coletado. Num projeto que interligue a fitoquímica com a farmacologia devese escolher para coleta a parte da planta que é utilizada na medicina popular. Coleta-se no mínimo $2 \mathrm{~kg}$ de material vegetal; no entanto, havendo boas condições de trabalho no laboratório, deve-se coletar entre 3-6 kg de material vegetal, buscando com isso, o isolamento em grandes quantidades de substâncias majoritárias, possibilitando suas avaliações farmacológicas. Durante a coleta, os seguintes itens devem ser cuidadosamente monitorados: separação e etiquetagem do material coletado; embalagem em sacos plásticos; transporte do material; pesagem do material úmido; secagem do material; pesagem do material seco; armazenagem; moagem; pesagem do material triturado; obtenção de extratos. A secagem pode ser realizada ao sol, à sombra ou em estufa, sempre com circulação de ar. Caso haja interesse no óleo essencial, deve-se evitar a secagem. A armazenagem deve ser feita em sacos plásticos, acondicionados em caixas de papelão guardadas em local seguro, com baixa umidade e temperatura. Desta maneira, previne-se reações de oxidação, hidrólise, ataque de microorganismos, entre outros. A moagem só deverá ser efetuada na ocasião da preparação dos extratos. A preparação de extratos é feita geralmente por percolação (método de extração a frio), Soxhlet (método de extração a quente) ou ácido-base, como mostra o Esquema 1. A extração via percolação é o processo de extração por solventes preferencialmente utilizado. Apresenta menor risco de reações químicas, na formação de artefatos, decorrentes da ação combinada entre solventes e temperaturas elevadas (utilizadas pelo sistema Soxhlet). Na extração ácido-base utiliza-se processos de partição entre solventes aquosos ácidos ou básicos e solventes orgânicos imiscíveis com água (éter, $\mathrm{CHCl}_{3}, \mathrm{AcOEt}$ ). Para uma única extração ( a frio ou a quente) usa-se geralmente um solvente polar $(\mathrm{MeOH}$ ou EtOH); para mais de uma extração utiliza-se três tipos de solventes: apolar (hexano ou éter de petróleo), de polaridade moderada $\left(\mathrm{CHCl}_{3}\right.$ ou $\left.\mathrm{CH}_{2} \mathrm{Cl}_{2}\right)$ e polar ( $\mathrm{MeOH}$ ou EtOH). No entanto, devido aos protocolos internacionais que condenaram o uso de solventes clorados, proibindo sua produção, estes solventes já não devem ser mais utilizados para a preparação de extratos, sendo portando, mais indicado, uma única extração utilizando $\mathrm{MeOH}$ ou EtOH.

A investigação preliminar de constituintes químicos representa, muitas vezes, um estímulo motivador da curiosidade, já que possibilita o conhecimento prévio dos extratos e indica a natureza das substân- 


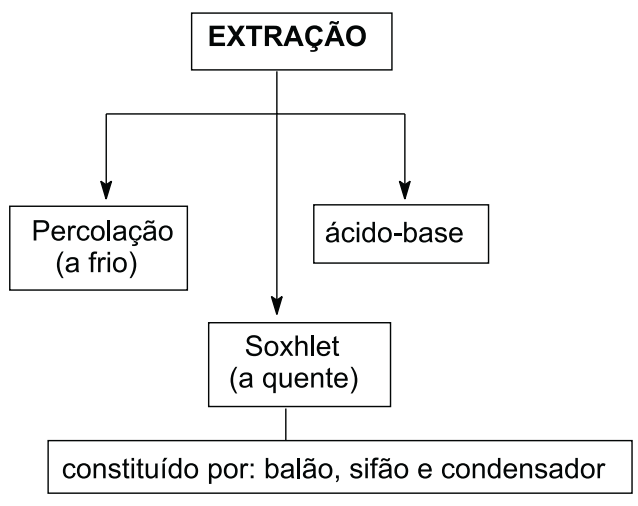

Esquema 1. Preparação geral de extratos através de extrações a frio, a quente e por partição utilizando-se solventes aquosos ácidos ou básicos e solventes orgânicos imiscíveis em água

cias presentes, facilitando a escolha de técnicas de fracionamento cromatográfico. As principais classes de constituintes químicos de plantas que podem ser detectadas com a aplicação de testes analíticos padrões ${ }^{29}$ são: ácidos graxos; terpenóides; esteróides; fenóis; alcalóides; cumarinas e flavonóides. Dados da literatura sobre as classes de substâncias detectadas em plantas do mesmo gênero da espécie que será investigada, devem ser analisados e catalogados. Avalia-se então, as técnicas de fracionamento cromatográfico, isolamento, purificação e caracterização específicos descritos previamente na literatura, para estas classes de substâncias. Esta avaliação deverá direcionar os trabalhos fitoquímicos que deverão ser realizados nos extratos previamente avaliados. O Esquema 2 mostra uma metodologia geral, adotada neste trabalho, para o isolamento de constituintes químicos. As separações cromatográficas são realizadas em coluna de gel de silica e as frações obtidas são monitoradas em cromatografia de camada fina (CCF) utilizando-se variados tipos de reagentes reveladores específicos ${ }^{30,31}$. As frações que se mostrarem semelhantes nas análises de CCF deverão ser reunidas e purificadas obedecendo técnicas de separação que poderão ser específicas ${ }^{30,31}$. O critério de pureza a ser adotado será aquele em que variando-se o sistema de solvente empregado, observa-se apenas uma única mancha uniforme em CCF. Outros procedimentos, no entanto, podem ser adotados. A escolha dos métodos e separação estão correlacionados com o tipo de extrato com o qual se está trabalhando e com as condições de infra-estrutura do laboratório, onde o trabalho está sendo desenvolvido.

A identificação dos compostos orgânicos deve ser feita através das seguintes análises espectroscópicas: 1) espectroscopia na região

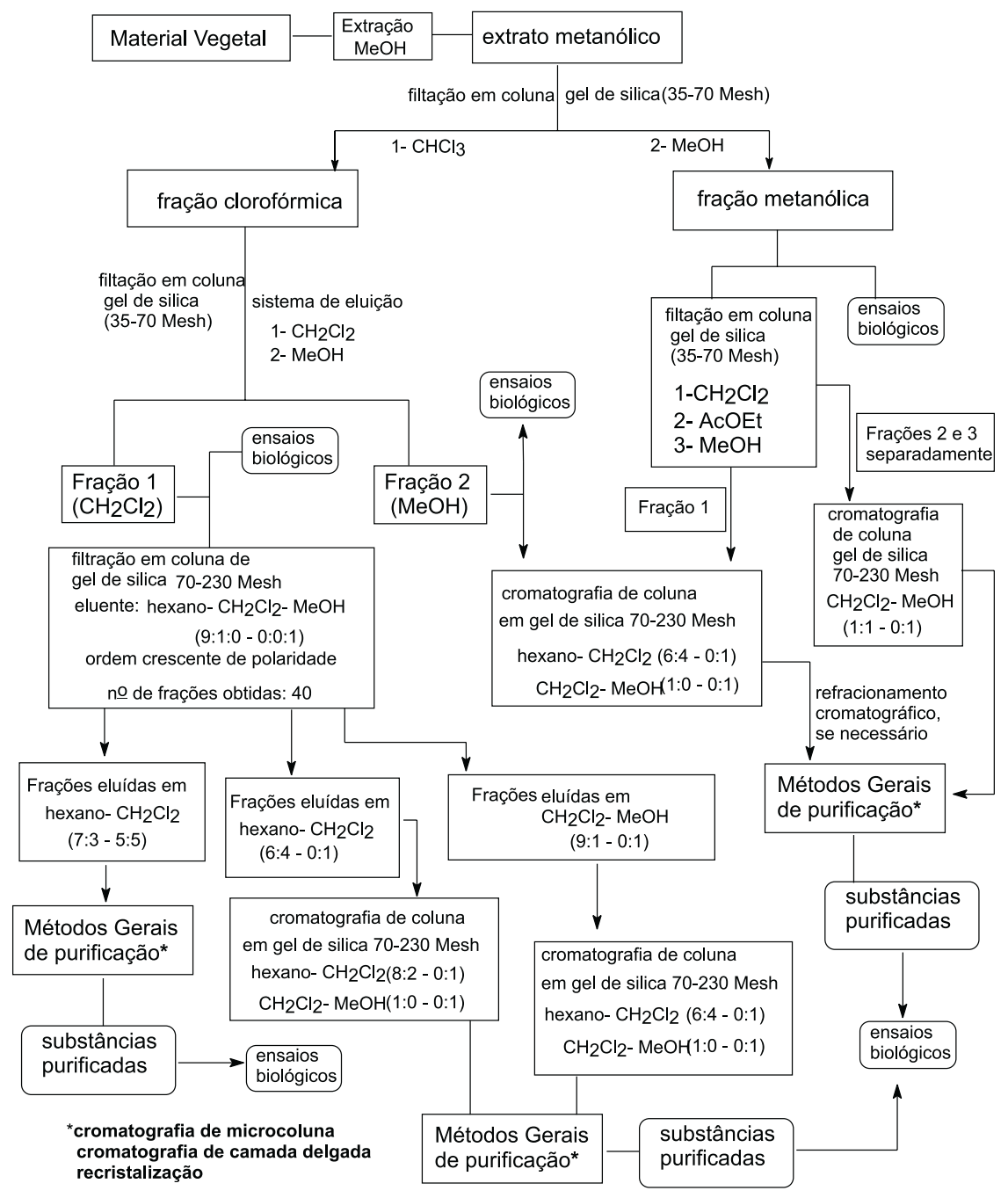

Esquema 2. Proposta fitoquímica para isolamento de constituintes químicos bioativos 
do infravermelho (IV) - o espectro de IV é interpretado em termos de presença ou ausência de grupos funcionais; 2) espectroscopia na região do ultravioleta (UV) - o espectro de UV define a presença de compostos que possuem ligações insaturadas em conjugação; 3) espectrometria de ressonância magnética nuclear de hidrogênio (RMN de ${ }^{1} \mathrm{H}$ ) e de carbono-13 (RMN de ${ }^{13} \mathrm{C}$ ) - determina a natureza e o ambiente químico de hidrogênios e carbonos, respectivamente. É a técnica mais importante para a investigação da estrutura molecular; 4) espectrometria de massas (EM) - fornece dados sobre o peso e a fórmula molecular e possibilita ainda, a identificação de fragmentos característicos da molécula.

O Esquema 2 integra trabalhos fitoquímicos e farmacológicos caracterizando desta forma, colaborações interdisciplinares. A avaliação farmacológica de extratos brutos, frações e substâncias isoladas deve seguir rigorosamente as indicações terapêuticas empíricas divulgadas por estudos etnobotânicos. A seleção correta de testes biológicos específicos, permitirá uma avaliação do uso terapêutico da espécie vegetal, fornecendo também, informações sobre a toxicidade da planta.

\section{Avaliação biológica}

A elucidação dos componentes ativos presentes nas plantas, bem como seus mecanismos de ação, vem sendo um dos maiores desafios para a química farmacêutica, bioquímica e a farmacologia ${ }^{32}$. As plantas contém inúmeros constituintes e seus extratos, quando testados podem apresentar efeitos sinérgicos entre os diferentes princípios ativos devido a presença de compostos de classes ou estruturas diferentes contribuindo para a mesma atividade. No estudo da atividade biológica de extratos vegetais é importante a seleção de bioensaios para a detecção do efeito específico. Os sistemas de ensaio devem ser simples, sensíveis e reprodutíveis.

Os bioensaios podem envolver organismos inferiores (microorganismos e microcrustáceos, entre outros), ensaios bioquímicos visando alvos moleculares (enzimas e receptores) e cultura de células animais ou humanas. Contudo, o teste adequado dependerá da doença alvo.

Os laboratórios de fitoquímica normalmente não estão preparados para a realização de ensaios biológicos elaborados. O ensaio da letalidade de organismos simples, como o microcrustáceo marinho Artemia salina Leach, permite a avaliação da toxicidade geral e é considerado um bioensaio preliminar no estudo de extratos e metabólitos especiais com potencial atividade biológica ${ }^{33,34}$.

$\mathrm{O}$ desenvolvimento de novas drogas bioativas necessita de modelos apropriados para a identificação de alvos moleculares que sejam fundamentais no crescimento celular seja in vitro ou in vivo. Entre os principais alvos intracelulares temos o DNA, RNA, microtúbulos e enzimas ${ }^{35}$.

Entre o grande número de ensaios possíveis para a obtenção de componentes ativos de plantas, selecionamos alguns testes in vivo e in vitro para avaliação da atividade antitumoral, antiestrogênica e antimutagênica, que constituem alvos de grande importância terapêutica.

\section{Avaliação da atividade antitumoral in vitro}

A atividade citotóxica das drogas pode ser estabelecida em cultura de células tumorais de várias linhagens através de métodos como: a) variações da morfologia celular ${ }^{36}$ - O efeito das drogas é avaliado por exame ao microscópio do dano ocorrido às células em cultura sem coloração específica por um tempo determinado; b) medidas da viabilidade celular ${ }^{37,38}$ - A viabilidade celular após exposição às drogas pode ser medida pela exclusão de corantes supravitais como o azul de tripan e a eosina. Esses ensaios baseiam-se na perda da inte- gridade da membrana celular das células não viáveis causando a captação do corante vital. Além desses ensaios, são utilizados também corantes para proteínas que se ligam eletrostaticamente aos íons das macromoléculas (proteínas) contendo cargas opostas. Por exemplo, sob condições ácidas, corantes aniônicos como a sulforrodamina B e o azul de bromofenol, ligam-se aos resíduos de aminoácidos básicos corando as proteínas celulares. Nesses ensaios, após a cultura de células na presença ou ausência de drogas, as células são fixadas com ácido tricloroacético, coradas e procede-se a leitura em espectrofotômetro após solubilização com base. Esta metodologia, utilizada atualmente no National Cancer Institute, Estados Unidos, se apresenta muito sensível para quantificar as proteínas celulares ${ }^{38}$; c) inibição do metabolismo celular - Neste caso são realizados uma série de ensaios utilizando técnicas diversas, tais como: c.1) ensaio do MTT $^{39,40}$ - Este ensaio baseia-se na medida do dano induzido pela droga no metabolismo celular de glicídeos usualmente através da atividade de desidrogenases. A atividade celular é quantificada pela redução do brometo de 3-[4,5-dimetiltiazol-2-il]-2,5difeniltetrazolium (MTT). As reações com o MTT são usadas para localizar a atividade de desidrogenases presentes em células viáveis. O sal de tetrazólio não reage diretamente com as desidrogenases, mas com os produtos da reação NADH ou NADPH que reduzem o MTT para a formazana correspondente. A quantificação da inibição enzimática é realizada espectrofotometricamente permitindo a obtenção dos valores de $\mathrm{IC}_{50}$ (concentração das drogas que inibem $50 \%$ da atividade enzimática); c.2) incorporação de radioisótopos ${ }^{38}-\mathrm{A}$ inibição da incorporação de precursores radioativos como os nucleosídeos $\left[{ }^{3} \mathrm{H}\right]$ timidina e $\left[{ }^{3} \mathrm{H}\right]$ uridina e o aminoácido $\left[{ }^{3} \mathrm{H}\right]$ leucina no DNA, RNA e proteínas, respectivamente, pode ser medida nas células após a exposição às drogas. A partir dos valores de percentagem de incorporação dos isótopos radioativos nas células tratadas com as drogas, em relação às células não tratadas (controle), são obtidos os valores de $\mathrm{IC}_{50}$ (concentração das drogas que inibem $50 \%$ da incorporação do isótopo radioativo).

\section{Avaliação da atividade antimutagênica in vitro}

O dano ao DNA é um evento fundamental no processo da carcinogênese e mutagênese. Muitas substâncias químicas podem ser avaliadas por sua ação mutagênica em bactérias. A metodologia mais utilizada para avaliação da atividade antimutagênica foi descrita por $\mathrm{Ames}^{41}$. O método de Ames consiste em um ensaio simples utilizando uma linhagem-teste de bactérias, especificamente mutantes de Salmonella typhimurium, incapazes de crescerem na ausência de histidina. Essas bactérias na presença de drogas mutagênicas causam novas mutações originando uma certa reversão na mutação original proporcionando a síntese de histidina permitindo assim, o crescimento bacteriano. Esse ensaio é realizado utilizando cultura de Salmonella mutante na presença ou ausência de homogenato de fígado de mamífero ${ }^{42}$ ou da fração microssomal ${ }^{43}$. A inibição da mutagenicidade é calculada pelo número de bactérias que foram revertidas em relação ao controle, levando-se em consideração as bactérias revertidas espontaneamente.

\section{Avaliação da atividade antiestrogênica in vitro}

Os bioensaios geralmente utilizados para avaliação da atividade antiestrogênica in vitro baseiam-se nos efeitos clássicos mediados pelo estrogênio ${ }^{44}$. Dentre esses ensaios destacam-se: a) ensaios de proliferação celular em linhagens estrogênio-dependentes; b) ensaios de ligação da droga ao receptor de estrogênio; c) análise da habilidade da droga induzir a expressão do gene no RNA mensageiro em linhagens de células sensíveis à estrogênio. 
O ensaio amplamente utilizado para avaliação de produtos naturais é o que emprega linhagens dependentes de estrogênio como as de câncer de mama MCF-7 ou T47-D ${ }^{44}$. A medida da proliferação celular na presença ou ausência da droga em estudo, pode ser realizada através da síntese de DNA com precursores radioativos ${ }^{38}$ ou da atividade metabólica das células viáveis, através por exemplo do ensaio do $\mathrm{MTT}^{39}$, já citados anteriormente.

\section{Avaliação da atividade antitumoral in vivo}

Basicamente podem ser utilizadas duas metodologias em função da natureza do tumor.

1. Tumores ascíticos ${ }^{45,46}$ - As células tumorais podem ser inoculadas via intraperitoneal (ip) em camundongos isogênicos. Após um tempo determinado inicia-se o tratamento com as drogas e o solvente utilizado (controle) segundo o esquema a ser determinado experimentalmente. Injeta-se as drogas ou o solvente via ip ou via sub-cutânea (sc). A eficiência do tratamento nos tumores é observada pela análise do aumento da sobrevida dos animais tratados (T) em comparação com a sobrevida dos animais controle (C) usando-se a expressão: \% T/C = [sobrevida em dias dos animais tratados $(\mathrm{T})$ com drogas / sobrevida dos animais controle (C)] x 100. A atividade antitumoral é considerada significativa quando o valor de $\% \mathrm{~T} / \mathrm{C} \geq 125$.

2. Tumores sólidos ${ }^{45}$ - Faz-se o transplante do pedaço do tumor ou injeta-se células tumorais via sc no dorso dos animais isogênicos. Após alguns dias inicia-se o tratamento dos animais com várias doses da droga em estudo seja por via ip ou sc. Em função do crescimento, faz-se a excisão e pesa-se os tumores. Através da média do peso dos tumores dos animais tratados em relação à média do peso dos tumores dos animais controle, verifica-se a significância do tratamento pelo teste de t-Student.

\section{Avaliação da atividade antiestrogênica in vivo}

Alguns ensaios biológicos para o estrogênio estão baseados no aumento do peso do útero de animais ${ }^{47}$. Os efeitos dos hormônios esteroidais resultam de suas interações com receptores protéicos presentes nos tecidos-alvo com função reprodutora como ovário, útero e glândula mamaria ${ }^{48,49}$. Um dos sistemas modelo utiliza ratas imaturas nas quais é injetado o hormônio esteroidal na presença ou ausência da droga em estudo. Após um determinado período, os animais são sacrificados e seus úteros pesados. O resultado positivo para a atividade antiestrogênica mostra a inibição do aumento do peso do útero, após análise estatística.

Com o objetivo de facilitar o entendimento da abordagem botânica, química e farmacológica na pesquisa de plantas medicinais, serão mostrados de maneira resumida, os estudos científicos de duas espécies amplamente utilizadas na medicina popular: a sacaca (Croton cajucara) e a copaíba (Copaifera L.) as quais mostraram através de colaborações interdisciplinares, correlação com todas as indicações terapêuticas empíricas divulgadas por estudos etnobotânicos.

\section{Croton cajucara Benth (Euphorbiaceae)}

O Croton cajucara, vulgarmente conhecido por sacaca (feitiço na língua Tupi), representa um recurso medicinal de grande importância no tratamento e cura de várias doenças. No estado do Pará, as folhas e cascas do caule desta planta são utilizadas em forma de chá ou pílulas, no combate a diabetes, diarréia, malária, febre, problemas estomacais, inflamações do fígado, rins, vesícula e no controle de índices elevados de colesterol ${ }^{50-53}$. A sacaca também é comercializada em farmácias de manipulação e, neste caso, o pó das cascas do caule é vendido em cápsulas (concentração aproximada de $250 \mathrm{mg}$ ). As folhas são comercializadas em feiras livres da cidade de Belém-PA, para distúrbios do fígado e auxilia na digestão, principalmente após ingestão de alimentação rica em gorduras. $O$ pó das folhas é vendido em farmácias de manipulação, com indicação hepatoprotetora, para tratamento de diabetes e para dietas de emagrecimento. Em alguns casos, este pó é comercializado em mistura com o pó do boldo do Chile. O chá das folhas é indicado em academias de ginástica da cidade de Belém para diminuição de peso corporal, em dietas de emagrecimento ${ }^{54,55}$. Porém, inúmeros casos de hepatite tóxica já foram notificados em hospitais públicos dessa cidade, devido ao uso prolongado deste chá, em dosagens concentradas $^{54,55}$. O uso recomendado do pó das cascas é $25 \mathrm{~g}$ de pó em 1000 $\mathrm{mL}$ de água, administrados 2 vezes ao dia durante 3-4 semanas, ou até que os sintomas da doença desapareçam. No caso do uso correto do chá das cascas, não encontra-se descritos na literatura, nenhum tipo de efeito colateral.

Apesar do Croton cajucara possuir uma grande representatividade na medicina tradicional ${ }^{50-53}$ da região Amazônica, até o final da década de 80, apenas uma avaliação farmacológica havia sido efetuada com está espécie ${ }^{56}$. Neste estudo, Cavalcante e colaboradores comprovaram a eficácia hipoglicêmica e hipolipidêmica da sacaca, em ratos. Em 1995, Oliveira e colaboradores, confirmaram o efeito hipolipidêmico em coelhos ${ }^{57}$. Com relação aos estudos fitoquímicos, o óleo essencial das folhas foi avaliado por Araújo e colaboradores ${ }^{58}$ e mais recentemente, por Lopes e colaboradores ${ }^{59}$. As cascas do caule desta espécie detém até o momento, o maior índice de estudos ${ }^{54,55,60-66}$. Curiosamente, observa-se que até 1992 apenas um trabalho fitoquímico ${ }^{60}$ havia sido desenvolvido no Brasil. Os demais trabalhos ${ }^{61-64}$ foram realizados fora do país, tendo sido liderados por pesquisadores japoneses. Objetivando resgatar o estudo científico do Croton cajucara elaborou-se um projeto de pesquisa que conectou experimentalmente a fitoquímica com a farmacologia. Desenvolveu-se um estudo que pudesse atender as necessidades de trabalhos de farmacólogos, monitorando a sacaca de modo que as suas informações terapêuticas empíricas fossem comprovadas ou não ${ }^{54,55,65,66}$. Foram utilizadas grandes quantidades de folhas e cascas do caule (partes da planta que são utilizadas na medicina popular) de árvores com idades variando entre $1 \frac{1}{2}-6$ anos, buscando o isolamento de substâncias majoritárias que pudessem vir a ter representatividade em testes biológicos. $\mathrm{O}$ estudo fitoquímico clássico realizado com $6 \mathrm{~kg}$ das cascas do caule de árvores com idades variando entre 4-6 anos, mostrou que esta parte da planta é rica em diterpenos do tipo clerodano $^{54,65}$. Neste estudo foi possível reisolar os clerodanos transdesidrocrotonina (DCTN); trans-crotonina (CTN); cis-cajucarina B; cajucarina A e cajucarinolida, previamente reportados ${ }^{62-64}$ em adição aos clerodanos inéditos trans-cajucarina B e sacacarina ${ }^{65}$. A estrutura química da sacacarina foi revisada utilizando técnicas de RMN (COSY, HMQC, HMBC e NOESY) em um equipamento Bruker DRX (600 MHz). A lactona envolvendo os átomos de carbono C-19 e C-20, foi confirmada para a estrutura 19,20-epoxi-20-oxo, denominada de isosacacarina ${ }^{66}$, sendo portanto, um isômero da sacacarina (19,20-epoxi-19-oxo).

O triterpeno ácido acetilaleuritólico (AAA) também foi reisolado das cascas do caule desta planta ${ }^{65}$. O estudo fitoquímico realizado em todas as partes da planta (raiz até folhas), mostrou que a DCTN também está presente nas raízes e caule. Este clerodano é a substância majoritária nas cascas do caule do Croton cajucara, com um teor incomum de 1,4\%. O isolamento de $85 \mathrm{~g}$ de DCTN possibilitou variados tipos de colaboração com grupos de farmacologia, que rastrearam através de experimentos específicos, todas as indicações terapêuticas empíricas da sacaca ${ }^{46,47,54,55,65-79}$. O 19-nor-clerodano 
DCTN mostrou correlação com grande parte das propriedades terapêuticas da planta, tendo sido possível evidenciar as seguintes propriedades farmacológicas: ação antiinflamatória e antinociceptiva ${ }^{67}$ (correlacionados com as indicações da planta para cura de inflamações em geral); efeito hipoglicemiante ${ }^{68,69}$ (tratamento de diabetes); atividade antiespasmódica ${ }^{54,70,71}$ (cura de diarréia); atividade antiulcerogênica ${ }^{54,72}$ (tratamento de problemas estomacais como azia, gastrite, úlcera gástrica). Evidenciou-se ainda, para este diterpeno, propriedades biológicas não mencionadas pelos usuários da planta, tais como: atividade antitumora ${ }^{46,54,73,74}$ e atividade antiestrogênica ${ }^{47,75}$. $\mathrm{O}$ efeito hipolipidêmico, correlacionado com a redução de índices elevados de colesterol, foi evidenciado no extrato hidroalcoólico das folhas da sacaca ${ }^{76}$. O efeito antimutagênico da DCTN foi comprovado em camundongos, utilizando-se testes citogenéticos do micronúcleo e de aberrações cromossômicas em células de medula óssea ${ }^{77-79}$. Outros estudos farmacológicos envolvendo avaliações citotóxica e antiulcerogênica da DCTN e do óleo essencial da sacaca, vêm sendo desenvolvidos no país, por outros pesquisadores ${ }^{80-83}$. Com o objetivo de investigar possíveis variações nos teores da DCTN em árvores com idades diferentes, monitorou-se a presença deste clerodano através de investigações fitoquímicas, realizadas nas cascas do caule de árvores com idades variando entre $1 \frac{1}{2}-6$ anos ${ }^{54,55,71}$, coletadas em épocas e ambientes diferentes. De acordo com o esperado, a DCTN foi isolada como componente majoritário nas cascas do caule da árvore com idade variando entre 3 e 6 anos. Nas árvores com idade de 3 anos, este clerodano foi isolado com um teor $(0,26 \%)$ inferior ao observado nas árvores com 4-6 anos (1,4\%). No entanto, sua presença não foi evidenciada nas cascas de árvores com $1 \frac{1}{2} \mathrm{de}$ idade. Nestas árvores, o ácido acetilaleuritólico (AAA) foi isolado como componente majoritário em árvores com idade de $1 \frac{1}{2}$ ano, provenientes de área com pouco grau de insolação $(0,18 \%)$. O rendimento de isolamento do AAA em árvores com $1 \frac{11}{2}$ de idade, provenientes de área exposta ao sol (grau máximo de insolação) foi $0,08 \%$. O triterpeno AAA foi também isolado em $0,08 \%$ de rendimento, nas árvores com idade variando entre 3-6 anos ${ }^{54,55,71}$.

Experimentos biológicos realizados com o AAA mostraram que este triterpeno possui atividade antiespasmódica ${ }^{54,70,71}$, ação antiinflamatória e antinociceptiva ${ }^{84,85}$. Esta substância mostrou-se inativa em testes que avaliam atividades antitumoral ${ }^{73}$ e antiulcerogênica ${ }^{72}$.

Através do estudo fitoquímico realizado com as folhas do Croton cajucara foi possível isolar e caracterizar três esteróides ( $\beta$-sitosterol, estigmasterol e 3,O-glicopiranosil- $\beta$-sitosterol), dois flavonóides (3,7,4'-tri-O-metilcanferol e 3,7,-di-O-metilcanferol) e um diterpeno do tipo 19-nor-clerodano (cajucarinolida) ${ }^{54,86}$. Dentro da programação de princípios ativos que está conectada à química orgânica sintética, obteve-se o derivado trans-crotonina (CTN) através de hidrogenação catalítica da DCTN (objetivando investigações farmacológicas específicas) ${ }^{54,71}$. Os dados espectroscópicos do produto hidrogenado mostraram-se iguais aos observados para a CTN, isolada como um dos componentes minoritários das cascas Croton cajucara. Experimentos realizados com a CTN-derivado mostraram que este diterpeno possui atividade antiulcerogênica ${ }^{5471,72}$, ação antiinflamatória e antinociceptiva ${ }^{84,85}$. A CTN difere da DCTN apenas pela ausência da ligação $\Delta^{3,4}$ do anel A do sistema decalínico; no entanto, esta substância mostrou-se inativa em testes que avaliam atividades antitumoral $^{46,73}$ e antiespasmódica ${ }^{54,70,71}$, atividades estas, que foram observadas ${ }^{54}$ para a molécula-mãe DCTN.

Outros derivados da DCTN estão sendo obtidos ${ }^{87,88}$ para que seja possível o estudo da relação estrutura/ atividade e dos mecanismos de ação deste diterpeno bioativo, que além de ser o componente majoritário nas cascas do Croton cajucara, foi o que apresentou a melhor correlação com grande parte das propriedades terapêuticas da sacaca.

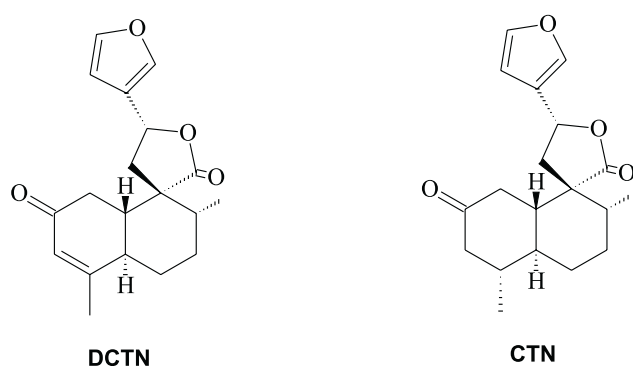

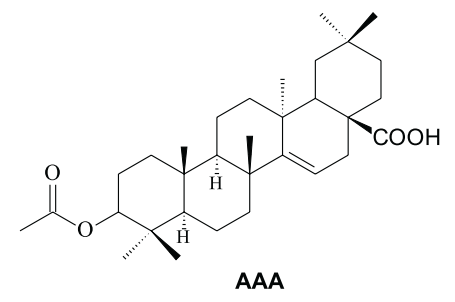

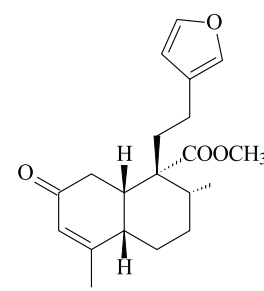

cis-cajucarina B

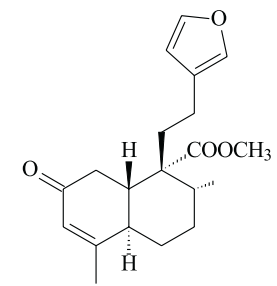

trans-cajucarina B

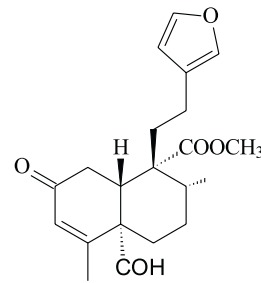

cajucarina $\mathbf{A}$

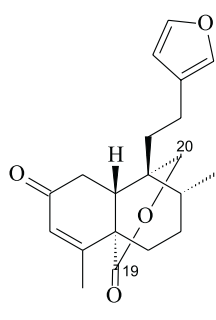

sacacarina

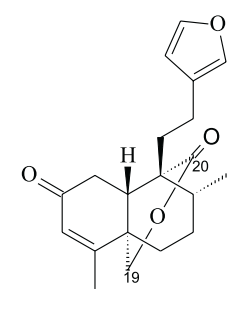

isosacacarina

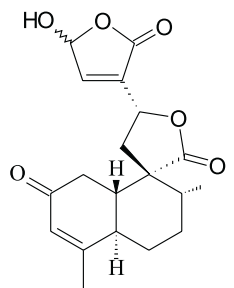

cajucarinolida

\section{Copaifera L. (Leguminosae-Caesalpinoideae)}

As copaíbas são árvores do gênero Copaifera L. (LeguminosaeCaesalpinoideae) que exudam do seu tronco um óleo resinoso chamado de óleo de copaíba, também descrito como bálsamo de copaíba ${ }^{89}$. Este gênero ocorre no norte da América do Sul, principalmente nos estados brasileiros do Pará e Amazonas ${ }^{90,91}$. Sua utilização como agente antiinflamatório e cicatrizante, é reportada desde o século XVI, quando os primeiros colonizadores das Américas relataram que as índias aplicavam este óleo no umbigo dos recém-nascidos e os guerreiros, após as batalhas, em seus ferimentos ${ }^{90}$. É do domínio da lenda que o conhecimento das propriedades medicinais do óleo de copaíba pelos índios, adveio da observação de que animais quando feridos esfregavam-se no tronco das copaibeiras para cicatrizarem suas feridas ${ }^{90}$. Hoje em dia, as aplicações medicinais do óleo de copaíba atinge todas as regiões do Brasil, sendo administrados oralmente e por aplicação tópica do óleo in natura ou em pomadas. Nos estados da região Norte é comum a prática da embrocação para tratar infecções na garganta ${ }^{92}$. Os óleos de copaíba vêm sendo amplamente utilizados como impor- 
tantes fitoterápicos na medicina tradicional, tendo indicação para diversas enfermidades ${ }^{89,90,92-97}$, tais como: estimulante, diurético, laxativo, expectorante, cicatrizante, antitetânico, antiemorrágico, antireumático, antiinflamatório, antiulcerogênico, antiséptico do aparelho urinário; tratamento de bronquites, doenças de origem sifilítica, moléstias de pele, leishmaniose, leucorréia, psoríase, diarréia, urticária, desinteria, infecções dos sistemas pulmonar e urinário, e ainda combate diferentes tipos de câncer. Apesar dos efeitos colaterais (irritação gastrointestinal, diarréia, sialorréia e depressão do sistema nervoso central) causados por altas doses do óleo, seu uso popular vem sendo intensificado ${ }^{92}$.

Diante das variadas aplicações terapêuticas dos óleos de copaíba, são muito reduzidos os estudos farmacológicos descritos até o momento, para estes óleos. A grande maioria destes estudos não indica a espécie de onde proveio o óleo, nem informam a época e o local de coleta. A ausência destas informações abre uma grande lacuna de incertezas em relação a autenticidade destes óleos, uma vez que estudos sobre a autenticidade de 16 diferentes tipos de óleos de copaíba comerciais, por cromatografia gasosa de alta resolução, mostraram que em grande parte, óleos de copaíba diferentes são misturados, tendo sido comprovado também adulteração, possivelmente com óleo de soja ${ }^{98}$. Além disso, estudos etnobotânicos relacionados aos óleos de copaíba, relatam que nem todas as árvores exudam óleos apropriados para o uso medicinal ${ }^{92}$. Na maior parte dos trabalhos publicados, a composição química dos óleos de copaíba não é fornecida. Em alguns trabalhos a espécie botânica não foi nem identificada, faz-se apenas menção ao óleo de copaíba comercial ${ }^{98,99}$. Estudos farmacológicos realizados com o óleo de Copaifera multijuga indicaram que a inibição de edema de pata de rato, varia com a composição química do óleo desta espécie, coletado em épocas diferentes ${ }^{99}$.

Entre as diversas propriedades medicinais atribuídas aos óleos de copaíba, as mais investigadas são as atividades antiinflamatória e

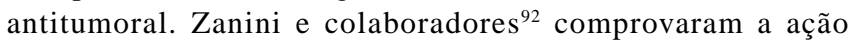
antiinflamatória de um óleo comercial sem identificação botânica, tendo observado baixa toxicidade $\left(\mathrm{DL}_{50} 3,79 \mathrm{~mL} / \mathrm{kg}\right.$ ), em experimentos realizados em ratos. Estudos recentes realizados com diversos óleos de copaíba comerciais ${ }^{101-102}$ e de Copaifera multijuga $a^{99}$ mostraram que a fração rica em hidrocarbonetos apresenta maior atividade antiinflamatória do que as frações de álcoois sesquiterpênicos e ácidos diterpênicos. Fernandes e colaboradores ${ }^{101}$ estudaram as atividades analgésica e antiinflamatória do óleo de Copaifera cearensis, e avaliaram os efeitos de ácido copálico, bisabolol e do éster metílico do ácido solidago, todos presentes em óleos de copaíba. Os resultados indicaram que a ação antiinflamatória e analgésica do óleo é maior do que a destes terpenos puros. Variados tipos de óleos comerciais apresentaram proteção contra a penetração de cercárias de Schistosoma mansoni ${ }^{102}$, ação cercaricida ${ }^{103,104}$, piscicida ${ }^{103}$, repelente de insetos ${ }^{105,106}$ e atividades antibacteriana ${ }^{107-109}$. Com relação a absorção cutânea, estudos realizados sobre a pele de camundongos mostraram que o óleo de copaíba é lentamente absorvido, por volta de noventa e dois minutos ${ }^{110}$.

O fracionamento cromatográfico de óleos de Copaifera langsdorfii guiado por bioensaios contra carcinoma CMI em camundongos, mostrou que os diterpenos colavenol e o ácido hardwickico apresentam potente atividade antitumoral, sem, contudo, apresentarem toxicidade ${ }^{111}$. Comprovou-se também a inibição do crescimento tumoral através da redução da formação dos nódulos de metástase no tecido pulmonar, pela administração in vivo e in vitro de óleos de C. multijuga ${ }^{112}$.

Estudados comparativamente, os óleos das espécies Copaifera multijuga, Copaifera cearensis e Copaifera reticulata apresentaram atividades antiinflamatória, antineoplásica e tripanossomicida ${ }^{113}$. No ensaio da atividade atividade tripanossomicida, os três óleos testa- dos foram colocados em contato $(250 \mathrm{mg} /$ poço) com cultura de formas tripomastigotas de Trypanossoma cruzi durante $48 \mathrm{~h}$. Observou-se que o óleo de Copaifera multijuga foi capaz de matar $100 \%$ dos parasitas enquanto que os óleos de Copaifera cearensis e Copaifera reticulata mataram $87 \%$ dos espécimens de Trypanossoma cruzi, indicando uma potente atividade ${ }^{113}$.

Propriedades antioxidantes são descritas para o extrato metanólico das cascas de Copaifera reticulata. Testado quanto à redução de radicais livres indutores de danos ao DNA, o extrato metanólico mostrou-se bastante ativo, apresentando $\mathrm{CI}_{50} 3 \mu \mathrm{g} / \mathrm{mL}$, menor que o padrão utilizado, catequina $\left(\mathrm{CI}_{50} 5 \mu \mathrm{g} / \mathrm{mL}\right)^{114}$. O potencial antioxidante reativo total deste extrato também foi analisado quanto à redução de radicais livres em ensaios de quimioluminescência, mostrando uma atividade de $7500 \mu \mathrm{M}$, em valores relativos ao padrão Trolox ${ }^{115}$. Extratos das sementes de Copaifera multijuga foram analisadas quanto às atividades hemolítica e aglutinante, tendo sido comprovada apenas a ação hemolítica ${ }^{116}$.

Como pode ser percebido através da descrição sumária destes estudos farmacológicos apresentados acima, com exceção dos diterpenos colavenol e o ácido hardwickico ${ }^{111}$, não há relação entre propriedades farmacológicas e substâncias químicas isoladas de óleos de copaíba. No entanto, vários dos compostos já isolados ou detectados nos óleos de copaíba já tiveram propriedades farmacológicas descritas na literatura. Entre os diterpenos, o ácido caurenóico é o mais estudado, tendo sido descrito como sendo um agente tripanossomicida ${ }^{117,118}$, apresentando $\mathrm{CI}_{50}$ de $0,5 \mathrm{mg} / \mathrm{mL}(1,66 \mathrm{mM})$ em ensaios in vitro contra a forma tripomastigota de T. cruzi ${ }^{117}$; bactericida ${ }^{119-121}$; larvicida contra Aedes aegypti ${ }^{122}$; estimulador de contração uterina ${ }^{123}$; antinociceptivo $\left(\mathrm{DI}_{50} 43 \mathrm{mmol} / \mathrm{kg}\right.$ com inibição máxima de $87 \%)^{124}$. Este diterpeno mostrou-se fracamente ativo contra a forma Bacillus subtilis ${ }^{122}$.

Para o $\alpha$-curcumeno e o $\beta$-bisaboleno, por exemplo, relatam-se as atividades antiulcerogênica ${ }^{125}$ e antiviral ${ }^{126}$. O $\beta$-bisaboleno também é descrito como abortivo ${ }^{127}$. O bisabolol é conhecido por ser responsável pelas propriedades antiinflamatória e analgésica da camomila (Matricaria chamomilla) ${ }^{128}$. Os sesquiterpenos $\beta$-elemeno, cariofileno e $\delta$-cadineno são agentes anticarcinogênicos ${ }^{129,130}$, sendo este último também bactericida (CMI $800 \mathrm{mg} / \mathrm{ml})^{130}$. O cariofileno apresentou as seguintes propriedades: antiedêmico ${ }^{131}$, fagorrepelente ${ }^{132}$, antiinflamatória $\left(\mathrm{CI}_{50}=100 \mu \mathrm{M}\right)^{131}$, antitumoral ${ }^{133}$, bactericida $^{134}$, insetífugo ${ }^{135}$ e espasmolítico ${ }^{136}$. Algumas destas atividades foram conferidas ao seu óxido-derivado ${ }^{131-133}$, também descrito como inseticida ${ }^{137}$.

\section{CONCLUSÕES}

As pesquisas com plantas medicinais envolvem investigações da medicina tradicional e popular (etnobotânica); isolamento, purificação e caracterização de princípios ativos (química orgânica: fitoquímica); investigação farmacológica de extratos e dos constituintes químicos isolados (farmacologia); transformações químicas de princípios ativos (química orgânica sintética); estudo da relação estrutura/atividade e dos mecanismos de ação dos princípios ativos (química medicinal e farmacológia) e finalmente a operação de formulações para a produção de fitoterápicos. A integração destas áreas na pesquisa de plantas medicinais conduz a um caminho promissor e eficaz para descobertas de novos medicamentos.

Os estudos etnofarmacológicos realizados com o Croton cajucara e Copaifera apresentados sumariamente neste artigo, englobam áreas interdisciplinares como etnobotânica, farmacologia e química orgânica: fitoquímica e sintética. Estes estudos procuram viabilizar de maneira segura, a validação prévia do uso terapêutico de plantas medicinais amplamente utilizadas na medicina tradicional de vários estados 
<smiles>COc1ccc(-c2oc3cc(OC)cc(O)c3c(=O)c2OC)cc1</smiles><smiles>COc1cc(O)c2c(=O)c(OC)c(-c3ccc(O)cc3)oc2c1</smiles>

7,4'-di-O-metilcanferol

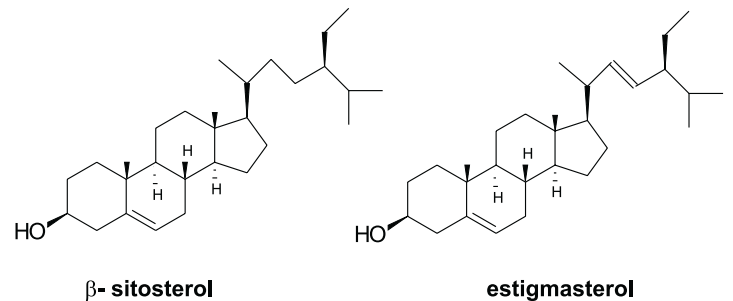

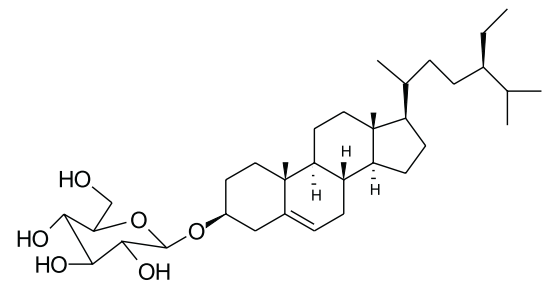

3-O- $\beta$-glicopiranosil- $\beta$-sitosterol

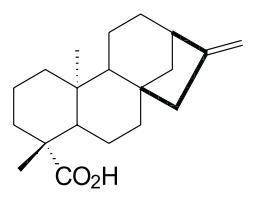

ácido caurenóico

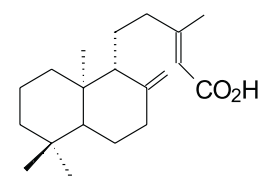

ácido copálico

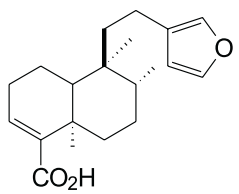

ácido hardwickiico<smiles>CC1=CCCC2C1CCC1C(CO)=C(C)CCC12</smiles>

colavenol

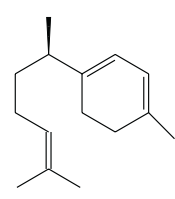

$\alpha$-curcumeno

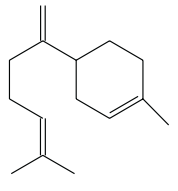

$\beta$-bisaboleno

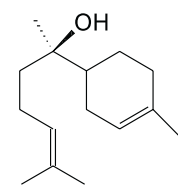

$\beta$-bisabolol

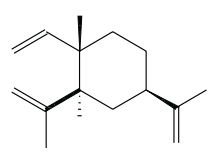

$\beta$-elemeno

do Brasil. Através dos resultados farmacológicos realizados em substâncias isoladas (DCTN, CTN e AAA, no caso do Croton cajucara), extratos e frações semi-purificadas (Croton cajucara e Copaifera) foi possível comprovar grande parte das indicações terapêuticas empíricas que os usuários destas plantas garantem existir.

\section{REFERÊNCIAS}

1. Amorozo, M. C.M.; Gely, A.; Uso de Plantas Medicinais por Caboclos do Baixo Amazonas; Barcarena: PA; Museu Paraense Emílio Goeldi, 1988, 4, p. 47.

2. Prance, G. T.; Out of the Amazon; HMSO: London, 1992, p. 83.

3. Schultes, R. E.; Lloydia 1962, 25, 257.

4. Posey, D. A. Em Ribeiro, B. G.; Suma Etnológica Brasileira-1. Etnobiologia; Editora Vozes: Petrópolis, 1986, p. 302.

5. Cardona, G. R.; La Foresta di Piume-Manuale di Etnoscienza; Laterza: Roma, 1985; p. 193.

6. Prance, G.T.; J. Ethnopharmacol. 1991, 32, 209.

7. Bruhn, J. G.; Acta Pharm. Nord. 1989, 1, 117.

8. Schultes, R. E; Lloydia 1963, 2, 67.

9. Schultes, R. E; Acta Amazonica 1963, 9, 209.

10. Schultes, R. E.; J. Ethnopharmacol. 1984, 11, 17.

11. Schultes, R. E.; J. Ethnopharmacol. 1993, 38, 129.

12. DeWitt, S. H.; Pharm. News 1994, $1,11$.

13. Houghton, R. A.; Curr. Biol. 1994, 4, 564.

14. Nielsen, J.; Chem. Ind. (London) 1994, 902.

15. King, S. R.; Tempesta, M. S. Em Ciba Foundation Symposium; Wiley: Chichester, 1994, 154, p. 197.

16. Balick, M. J. Em Ciba Foundation Symposium; Wiley: Chichester, 1990, 154 , p. 22.

17. Soejarto, D. D. Em American Chemical Society Symposium Series; Washington: DC, 1993, 534, p. 96.

18. King, S. R. Em Society for Applied Anthropology; Greaves, T.; ed; Oklahoma City: OK, 1994, p. 69.

19. Elisabetsky, E.; Moraes, J. A. R. Em The First International Congress of Ethnobiology; Poesy, D. A.; Overal, W. L.; eds; Belém: Brasil, 1988, 2, p. 111.

20. Cordell, G. A.; Pharmazie 1990, 30, 169.

21. Cordell,G. A.; Beecher, C. W.; Pezzuto, J. M.; J. Ethnopharmacol. 1991 $32,117$.

22. Cordell, G. A. Em Bioactive Natural Products - Part A; Atta-ur-Rahman; Bash, F. Z.; eds. Elsevier Science Publishers: Amsterdam, 1993, 13, p. 629

23. Cordell, G. A.; Farnsworth, N. R.; Beecher, C. W.; Kinghorn, A. D.; Pezzuto, J. M.; Wall, M. E.; Wani, M. C.; Brown, D. M.; Harris, T. J. R.; Lewis, J. A.; O’Neill, M. J.; Tait, R. M. Em American Chemical Society Symposium Series; Kinghorn, A. D.; Balandrin, M. F.; eds; Washington: DC, 1993, 534, p. 191.

24. Cox, P. A.; Balick, M. J.; Sci. Am. 1994, June, 42.

25. Holland, B. K.; Nature 1994, 369, 702.

26. Bruhns, A.; The Ottawa Citizen 1994, April 16, A6.

27. Cordell, G. A.; Phytochemistry 1995, 40, 1585.

28. Malone, M. H.; J. Ethnopharmacol. 1983, 8, 127.

29. Matos, F. J. A.; Sousa, M. P.; Souza, T. T.; Rev. Bras. Farm. 1971, 50,65

30. Zweig, G.; Sherma, J.; Handbook of Chromatography; Chemical Rubber: Cleveland, 1972.

31. Poole, S. K.; Anal. Chim. Acta 1990, 236, 3.

32. Gebhardt, R.; Planta Med. 2000, 66, 99.

33. Mayer, B. N.; Ferrigni, N. R.; Jacobson, J. E.; Nichols, D. E.; McLaughein, J. L.; Planta Med. 1982, 45, 31 .

34. Cavalcanti, M. F.; Oliveira, M. C. F.; Velandia, J. R.; Echevarria, A.; Quim. Nova 2000, 23, 20.

35. Lodish, H.; Berk, A.; Zipursky, S. L.; Matsudaira, P.; Baltimore, D. Darnell, J.; Molecular Cell Biology, W. H.; Freeman and Company Inc.: New York, 1999, p. 475.

36. Skehan, E.; Cell Growth and Apoptosis. A Practical Approach; ed. G. P. Studzinski IRL Press: Oxford, 1995, p. 169.

37. Skehan, P.; Storeng, R.; Scudiero, D.; Monks, A.; Mcmahon, J.; Vistica, D.; Warren, J. T.; Bokesch, H.; Kenney, S.; Boyd, M. R.; J. Natl. Cancer Inst. 1990, 82, 1107.

38. Wilson, A. P.; Animal Cell Culture: A Practical Approach; IRL Press: Oxford, 1987, cap. 8, p. 183.

39. Mossman, T.; J. Immunol. Methods 1983, 65, 55.

40. Carmichel, J.; DeGraff, W. G.; Gazdar, A. F.; Minna, J. D.; Mitchell, J. B.; Cancer Res. 1987, 47, 936.

41. Ames, B. N.; Science 1979, 204, 587.

42. Stryer, L.; Bioquímica, 4 ed., Guanabara Koogan: Rio de Janeiro, 1996, p. 776.

43. Diel, P.; Smolnikar, K.; Michna, H.; Planta Med. 1999, 65, 197.

44. Soto, A. M.; Sonnenschein, C.; Chung, K. L.; Fernandez, M. F.; Olea, N.; Serrano, F. O.; Environ. Health Perspect. 1995, 103, 113.

45. Geran, R. I.; Greenberg, N. H.; MacDonald, M. M.; Schumacher, A. M.; Abbot, R. J.; Cancer Chemotheraphy Rep. 1972, 3, 1. 
46. Grynberg, N. F.; Echevarria, A.; Lima, J. E.; Pamplona, S. G. S. R.; Pinto, A. C.; Maciel, M. A. M.; Planta Med. 1999, 65, 386.

47. Costa, A. M.; Silva, J. C. R.; Campos, A. R.; Rao, V. S. N.; Maciel, M. A M.; Pinto, A. C.; Phytother. Res. 1999, 13, 1.

48. De Vita, V. J.; Hellman, S.; Rosenberg, S. A.; Cancer Principles and Practice of Oncology, $5^{\mathrm{a}}$ ed., Lippincott-Raven Publishers, Philadelphia: New York, 1997, 1, p. 375.

49. Nelson, D. L.; Cox, M. M.; Lehninger Principles of Biochemistry, $3^{\mathrm{a}}$ ed., Worths Publishers: New York, 2000, p. 949.

50. Van Den Berg, M. E.; Plantas Medicinais na Amazônia- Contribuição ao seu Conhecimento Sistemático; Gráfica Editora Falangola: Belém, 1982, p. 158.

51. Di Stasi, L. C.; Santos, E. M. G; Santos, C. M.; Hiruma, C. A.; Plantas Medicinais da Amazônia; Editora UNESP: São Paulo, 1989, p. 127

52. Di Stasi, L. C.; Hiruma, C. A.; Guimarães, E. M.; Santos, C. M.; Fitoterapia 1994, 65, 529.

53. Martins, J. E. C.; Plantas Medicinais de uso na Amazônia; Centro de Estudos Jurídicos do Pará: Belém, 1989, p. 92.

54. Maciel, M. A. M.; Pinto, A. C.; Arruda, A. C., Pamplona; S. G. S. R., Vanderlinde; F. A.; Lapa, A. J.; Cólus, I. M. S.; Echevarria, A.; Grynberg, N. F.; Farias, R. A. F.; Luna Costa, A. M.; Rao, V. S. N.; J. Ethnopharmacol. 2000, 70, 41

55. Maciel, M. A. M.; Pinto, A. C.; Brabo, S. N.; Arruda, A. C.; Rev. Univ Rural, Sér. Ciênc. Exatas e da Terra 1998, 18/20, 17.

56. Cavalcante, F. L. M.; Reunião Anual da Federação de Sociedades de Biologia Experimental (FESBE), Caxambu, Brasil, 1988.

57. Oliveira, M. C.; Borrás, M. R. L.; Silva, E. A.; Roland, I. A.; Reunião Anual da Federação de Sociedades de Biologia Experimental (FESBE), Serra Negra, Brasil, 1995.

58. Araujo, V. C.; Corrêa, G. C.; Maia, J. G. S.; Silva, M. L. S.; Gottlieb, O. R.; Marx, M. C.; Magalhães, M. T.; Acta Amazonica 1971, 1, 45.

59. Lopes, D.; Bizzo, H. R.; Sobrinho, A. F. S.; Pereira, M. V. G.; $30^{\text {th }}$ International Symposium on Essential Oils, Leipzig, 1999.

60. Simões, J. C.; Silva, A. J. R.; Serruya, H.; Bentes, M. H. S.; Ciência e Cultura 1979, 31, 1140.

61. Itokawa, H.; Ichihara; Y.; Kogima, H.; Watanabe, K.; Takeya, K. Phytochemistry 1989, 28, 1667.

62. Itokawa, H.; Ichihara, Y.; Shimizu, M.; Takeya, K.; Motidome, M.; Chem. Pharm. Bull. 1990, 38, 701.

63. Ichihara, Y.; Takeya, K.; Hitotsuyanagi, Y.; Morita, H.; Okuyama, S.; Suganuma, M.; Fujiki, H.; Motidome, M.; Itokawa, H.; Planta Med. 1990, $58,549$.

64. Kubo, I.; Asaka, Y.; Shibata, K.; Phytochemistry 1991, 30, 2545

65. Maciel, M. A. M.; Pinto, A. C.; Brabo, S. N.; Silva, M. N.; Phytochemistry 1998, 49, 823 .

66. Maciel, M. A. M.; Pinto, A. C.; Kaiser, C. R.; Veiga Jr., V. F.; Martins, J R.; J. Ethnopharmacol., no prelo.

67. Carvalho, J. C. T.; Silva, M. F. C.; Maciel, M. A. M.; Pinto, A. C.; Nunes, D. S.; Lima, R. M. L.; Bastos, J. K.; Sarti, S. J.; Planta Med. 1996, 62, 402.

68. Farias, R. A. F.; Neto, M. F. O.; Viana, G. S. B.; Rao, V. S. N.; Silveira, E. R.; XIV Simpósio de Plantas Medicinais do Brazil, Florianópolis, Brasil, 1996.

69. Farias, R. A. F.; Rao, V. S. N.; Viana, G. S. B.; Silveira, E. R.; Maciel, M. A. M.; Pinto, A. C.; Planta Med. 1997, 66, 558.

70. Maciel, M. A. M.; Tese de Doutorado, Universidade Federal do Rio de Janeiro, Brasil, 1997, p. 171.

71. Maciel, M. A. M.; Pinto, A. C.; Pamplona, S. G. S. R.; Vanderlinde, F. A.; Lapa, A. J.; Carvalho, J. C. T.; Echevarria, A.; Grynberg, N. F.; Farias, R. A. F.; Luna Costa, A. M.; Rao, V. S. N.; XV Simpósio de Plantas Medicinais do Brasil, Águas de Lindóia, Brasil, 1998.

72. Vanderlinde, F. A.; Souccar, C.; Pinto, A. C.; Maciel, M. A. M.; Pamplona, S. G. S. R.; Lapa, A. J.; XV Congresso Latino Americano de Farmacologia Colômbia, 1997.

73. Maciel, M. A. M.; Tese de Doutorado, Universidade Federal do Rio de Janeiro, Brasil, 1997, p. 165.

74. Maciel, M. A. M.; Pinto, A. C.; Grynberg, N.; Echevarria, A.; XI Reunião Anual da Federação de Sociedades de Biologia Experimental, Caxambu, Brasil, 1996.

75. Luna Costa, A. M.; Rao, V. S. N.; Maciel, M. A. M.; Pinto, A. C.; XIIIth International Congress of Pharmacology, München: Germany, 1998.

76. Farias, R. A. F.; Neto, M. F. O.; Viana, G. S. B.; Rao, V. S. N.; Phytother. Res. 1996, 10, 697

77. Âgner, A. R.; Maciel, M. A. M.; Pinto, A. C. P.; Pamplona, G. R. S.; Cólus, M. S.; $44^{\circ}$ Congresso Nacional de Genética- Genetics and Molecular Biology, Águas de Lindóia, Brasil, 1998.
78. Âgner, A. R.; Maciel, M. A. M.; Pinto, A. C. P.; Pamplona, G. R. S.; Cólus, M. S.; $44^{\circ}$ Congresso Nacional de Genética- Genetics and Molecular Biology, Águas de Lindóia, Brasil, 1998.

79. Âgner, A. R.; Maciel, M. A. M.; Pinto, A. C.; Pamplona, G. R. S.; Cólus, M. S.; Teratog. Carcinog. Mutagen. 1999, 19, 377.

80. Hiruma-Lima, C. A.; Gracioso, J. S.; Rodriguez, J. A.; Haun M., Nunes D. S.; Souza Brito, A. R.; J. Ethnopharmacol. 2000, 69, 229.

81. Bighetti, E. J.; Hiruma-Lima, C. A.; Gracioso, J. S.; Brito, A. R. S.; J. Pharm. Pharmacol. 1999, 51, 1447.

82. Hiruma-Lima, C. A.; Spadari-Bratrfisch, R. C.; Grassi-Kassisse, D. M.; Brito, A. R.; Planta Med. 1999, 65, 325.

83. Rodriguez, J. A.; Haun, M.; Planta Med. 1999, 65, 522

84. Perazzo, F. F.; Rodrigues, M.; Carvalho, J. C. T.; Maciel, M. A. M.; Pinto, A. C.; Arruda, A. C.; Pamplona, S. G. S. R.; III Jornada Paulista de Plantas Medicinais, Campinas, Brasil, 1997.

85. Perazzo, F. F.; Rodrigues, M.; Carvalho, J. C. T.; Maciel, M. A. M.; Pinto, A. C.; Arruda, A. C.; Pamplona, S. G. S. R.; Antoniássi, N. C.; II World Congress on Medicinal and Aromatic for Human Welfare, Mendoza, Argentina, 1997.

86. Maciel, M. A. M.; Pinto, A. C.; Nunes, D. S.; Resumos da $18^{a}$ Reunião Anual da Sociedade Brasileira de Química, Caxambu, Brasil, 1995.

87. Garden, S. J.; Martins, J. R; Pinto, A. C.; Maciel, M. A. M.; Resumos da $22^{a}$ Reunião Anual da Sociedade Brasileira de Química, Poços de Caldas, Brasil, 1999.

88. Martins, J. R.; Dissertação de Mestrado, Universidade Federal do Rio de Janeiro, Brasil, 2000

89. Deussen, E.; Scientia Pharmacol. 1939, 10, 69.

90. Salvador, V.; História do Brasil: 1500-1627, 6ª . ed., Melhoramentos: São Paulo, 1975, p. 65

91. Pio Corrêa, M.; Dicionário das Plantas Úteis do Brasil; Ministério da Agricultura: Rio de Janeiro, 1931.

92. Basile, A. C.; Sertié, J. A.; Freitas, P. C. D.; Zanini, A. C.; J. Ethnopharmacol. 1988, 22, 101.

93. Alencar, J. C.; Acta Amazonica 1982, 12, 75.

94. Freise, F. W.; Süddeut. Apot-Ztg. 1937, 77, 11.

95. Le Cointe, P.; L'Amazonie brésilien.Le pays, ses habitants, ses ressources; Paris, 1922, 2, p. 493

96. Barriga, H. G.; Flora Medicinal de Colombia. Botanica Medica; Tercer mundo editores; Bogotá, 1992, 3, p. 559.

97. Veiga Jr., V. F.; Pinto, A. C.; Quim. Nova 2002, 25, 273

98. Veiga Jr., V. F.; Pinto, A. C.; Patitucci, M. L.; Quim. Nova 1997, 20, 612.

99. Veiga Jr., V. F.; Pinto, A. C.; Calixto, J. B.; Zunino, L.; Patitucci, M. L.; Phytother. Res. 2001, 15, 476.

100. Veiga Jr., V. F.; Pinto, A. C.; Calixto, J. B.; International Joint Symposium on Chemistry, Biological and Pharmacological Properties of Medicinal Plants from the Americas, Panama, Republic of Panama, 1997.

101. Fernandes, R. M.; Pereira, N. A.; Paulo, L. G.; Rev. Bras. Farm. 1992, 73, 53.

102. Gilbert, B.; Mors, W. B.; Baker, P. M.; Tomassini, T. C.; Pellegrino, J.; An. Acad. Brasil. Ciênc. 1972, 44, 423.

103. Mahajan, J. R.; Ferreira, G. A. L.; Pellegrino, J.; An. Acad. Brasil. Ciênc. 1972, 44, 429.

104. Mahajan, J. R.; Ferreira, G. A. L.; An. Acad. Brasil. Ciênc. 1971, 43, 611

105. Lacey, L. A.; Schreck, C. E.; McGovern, T. P.; Mosquito News 1981, 41, 376.

106. Jones, S. C.; Carter, F. L.; Mauldin, J. K.; Env. Entomol. 1983, 12, 458

107. Opdyke, D. L.; Food Cosmet. Toxicol. 1976, 14(Suppl.), 687.

108. Marussella, J. C.; Sicurella, N. A.; J. Am. Pharm. Assoc. 1960, 49, 692.

109. Abdullim, K. H.; Uchen. Zap. Kazanski Vet. 1962, 48, 75.

110. Meyer, F.; Meyer, E.; Arzneimittel-Forsch 1959, 9, 516.

111. Ohsaki, A.; Yan, L. T.; Ito, S.; Edatsugi, H.; Iwata, D.; Komoda, Y.; BioInorg. Med. Chem. Lett. 1994, 4, 2889.

112. Lima, S. R. M.; Fernandes, P. D.; Veiga Jr., V. F.; Pinto, A. C.; III Reunião da Sociedade Latino-Americana de Fitoquímica, Gramado, Brasil, 1999.

113. Henriques, M. G. M. O.; Rosas, E. C.; Carvalho, M. V.; Veiga Jr., V. F.; Pinto, A. C.; XV Simpósio de Plantas Medicinais, Águas de Lindóia, Brasil, 1998.

114. Desmarchelier, C.; Coussio, J.; Ciccia, G.; Phytother. Res. 1997, 11, 460.

115. Desmarchelier, C.; Repetto, M.; Coussio, J.; Llesuy, S.; Ciccia, G.; In. J. Pharmacog. 1997, 35, 288.

116. Alves, T. M. A.; Chaves, P. P. G.; Santos, L. M. S. T.; Nagem, T. J.; Murta, S. M. F.; Ceravolo, I. P.; Romanha, A. J.; Zani, C. L.; Planta Med. 1995 $61,85$.

117. Alves, T. M. A.; Chaves, P. P. G.; Santos, L. M. S. T.; Nagem, T. J.; Murta, S. M. F.; Ceravolo, I. P.; Romanha, A. J.; Zani, C. L.; Planta Med. 1995, 61,85 . 
118. Batista, R.; Chiari, E.; Oliveira, A. B.; Planta Med. 1999, 65, 283.

119. Lwande, W.; MacFoy, C.; Okecj, M.; Dele Monache, F.; Marini-Bettólo, G. B.; Fitoterapia 1985, 56, 126.

120. Velikova, M.; Bankova, V.; Tsvetcova, I.; Kujumgiev, A.; Marcucci, M. C.; Fitoterapia 2000, 71, 693.

121. Oguntimein, B. O.; Fitoterapia 1987, 58, 411.

122. Slimestad, R.; Marston, A.; Mavi, S.; Hostettmann, K.; Planta Med. 1995, $61,562$.

123. Page, J. E.; Balza, F.; Nishida, T.; Towers, G. H. N.; Phytochemistry 1992, 31,3437 .

124. Block, L. C.; Santos, A. R. S.; Souza, M. M.; Scheidt, L.; Yunes, R. A.; Santos, M. A.; Dele Monache, F.; Cechinel Filho, V.; J. Ethnopharmacol. 1998, 61, 85.

125. Yamahara, J.; Yakugaku Zasshi 1992, 112, 645.

126. Denyer, C. V.; Jackson, P.; Loakes, D. M.; Ellis, M. R.; Yound, D. A. B.; J. Nat. Prod. 1992, 57, 658.

127. Pei-Gen, X.; Nai-Gong, W.; J. Ethnopharmacol. 1991, 32, 167.
128. Zekovic, Z.; Pekie, B.; Lepojevic, Z.; Petrovic, L.; Chromatographia 1994, $39,587$.

129. Leewenberg, A. J. M.; Medicinal and Poisonous Plants of the Tropics; ed. Pudoc: Wageningen, 1987.

130. Kubo, I.; Muroi, H.; J. Agric. Food Chem. 1993, 41, 1102.

131. Shimizu, M. ; Chem. Pharm. Bull. 1990, 38, 2283.

132. Keeler, R. F.; Tu, A. T.; Toxicological of Plant and Fungal Compounds; Handbook of Natural Toxins; Marcel Dekker: Nova York, 1991, p. 665.

133. Zheng, G.Q.; Kenney, P. M.; Lam, L. K. T.; J. Nat. Prod. 1992, 55, 999.

134. Kang, R.; Helms, R.; Stout, M. J.; Jaber, H.; Nakatsu, T.; J. Agric. Food Chem. 1992, 40, 2328.

135. Jacobson, M.; Glossary of Plant-Derived Insect Deterrents, CRC Press: Boca Raton, 1990.

136. Duke, J. A.; Handbook of Biologically Active Phytochemicals and their Activities, CRC Press: Boca Raton, 1992.

137. Bettarini, F.; Borgonovi, G. E.; Insect Sci. Applic. 1991, 14, 93. 